\title{
Frontiers of Monetary Policy: Global Trends and Russian Inflation Targeting Practices
}

Ksenia Yudaeva, Bank of Russia

The IMF published in April 2018 the book Advancing the Frontiers of Monetary Policy written by its experts and edited by Tobias Adrian, Douglas Laxton, and Maurice Obstfeld, providing a rare chance to learn the views of people who could be called the architects of inflation targeting. The book deals with practical issues of using this monetary policy regime which has quickly gained wide acceptance and is currently employed by central banks of most countries in the world. Some issues of inflation targeting policy further improvements brought up in the book are also relevant to Russia.

Keywords: inflation targeting, monetary policy, central bank communications, financial stability, Bank of Russia

JEL: E58, E37, E47

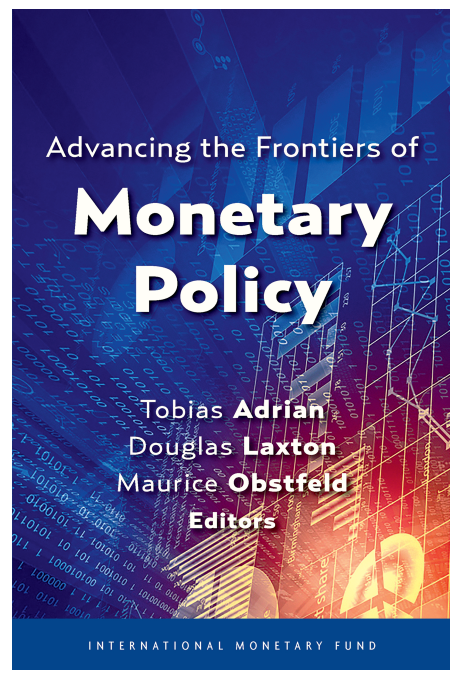

Adrian T., Laxton D., and Obstfeld M., editors. (2018). Advancing the Frontiers of Monetary Policy. Washington, DC: International Monetary Fund
Citation: Yudaeva, K. (2018). Frontiers of Monetary Policy: Global Trends and Russian Inflation Targeting Practices. Russian Journal of Money and Finance, v. 77(2), pp. 95-100.

doi: $10.31477 /$ rjmf.201802.95

\section{Evolution of central bank policies}

Aside from the general introduction, the book consists of two parts. The first part touches upon inflation targeting principles and practices. The authors show how clarity of goals and transparency help manage inflation expectations; how communications policy, in particular the announcement of the current and signals about future interest rate policy as well as the 
publication of forecasts help better explain monetary policy goals and ways of their achievement; which parameters a central bank's main forecasting model should feature; which specific liquidity management instruments it has at its disposal. The book also focuses on the relationship between monetary policy and attaining financial stability, paying attention, to, among other things, macroprudential policy instruments.

The second part of the book examines in depth inflation targeting experience of individual countries: Canada, the Czech Republic, India, and the USA. The authors emphasize monetary policy constraints where nominal interest rates are close to zero, the role of the regulator's reputation, the need for decision-making transparency, and the threat of external shocks to inflation targeting success.

The common subject of all the contributions is the evolution, options of practical implementation and possible paths of further improvements in monetary policy which is officially referred to as the inflation targeting regime. It was originally used about 30 years ago in New Zealand, almost immediately followed by Canada. In the 1990s - early 2000s, this monetary policy regime became widespread in both advanced and emerging markets. It is only a handful of highly or moderately developed economies that rely on other monetary policy regimes, which is usually attributed to the specifics of their conditions. Less developed countries are also experimenting with inflation targeting, but its fullfledged use requires a certain level of markets' development to be achieved.

Over its almost 30-year history, the inflation targeting regime has undergone a certain evolution. It has, above all, affected the very concept of reaching and deviating from policy goals. Thirty years ago, the key problem of both developed and emerging economies was high inflation, while this regime helped bring it down to steadily low levels. To reach these levels, central banks at first quite rigorously followed the rule of achieving the inflation target. But as economies adapted to the inflation targeting regime and anchoring inflation expectations around the target, central banks started to use a more flexible approach to the policy of reaching the inflation target. The authors call this approach inflation forecast targeting. It implies that in conducting their policies, central banks take into account the nature of inflation deviation from the target and a balance of risks to inflation and economic growth, constructing a relevant forecast and conducting a policy which helps implement it.

This approach required central banks to introduce substantial changes to both their internal procedures and the system of communications with the market and public in general.

Constructing a forecast credible to the expert community requires a central bank to take significant efforts to develop research and analysis capacity of its own. All central banks conducting inflation targeting policy have research departments dealing with model construction, data analysis and forecasting. These units keep up a constant dialogue with research and expert communities, 
take part in conferences and have their research papers published in scientific journals. In times when central banks pursued fixed exchange rate policies, these economic analysis and modeling competencies were not needed.

Nor was a special communications policy required in the epoch of fixed exchange rates later replaced by a period of floating exchange rates with no clear targets. On the contrary, central banks often adhered to the principle of secrecy. They did not even disclose their operating targets for money market interest rates, let alone forecasts. But the switch to inflation forecast targeting has brought about a major change.

Today, communications are regarded as a key element of central bank policies. A minimum set of communications includes the publication of board of directors' (or monetary policy committees') interest rate decisions immediately after their meetings, with the rationale for the board of directors or monetary policy committee's decisions explained practically at once. This could be provided in the form of either a press release or a press conference of the chairman of the board of directors or monetary policy committee. Most countries also publish a more detailed monetary policy report (in some countries this is called an inflation report), many publish the details of discussion at the board of directors meeting (the so-called minutes).

As the inflation targeting regime has been used in economies different in levels and depth of market development, this has resulted in different operating procedures. Inflation targeting implies that the policy goal is maintaining a certain average inflation level and using one instrument for this purpose - that of short-term money market interest rates. All of an economy's other interest rates depend on short-term interest rates, the inflation target and communications regarding future policy. This is how the transmission mechanism of monetary policy works. But it is only interest rates on its own instruments rather than money market interest rates that a central bank can set directly. Therefore, all central banks using the inflation targeting regime have an operating procedure, enabling target money market rates to be reached. The book we are reviewing classifies all possible options of these operating procedures (or mechanisms):

1) targeting the market interest rate in the middle of the interest rate corridor through central bank's regular (on a daily or some other basis) operations (with the policy rate linked to the central bank's main instrument), and providing reserve requirements;

2) a multilevel lower bound (floor) of interest rates;

3) a lower bound (floor) of interest rates.

The book provides a description and classification of these regimes from the perspective of their clarity to the market, effectiveness in reaching policy goals, risks and costs to a central bank.

Without going into specifics, we will note that the Russian Central Bank has opted for the operating regime of the first type. The standing interest rate corridor 
for deposit and loan transactions determines the rates' maximum deviation from the target. Weekly loan and deposit auctions as well as "fine-tuning" auctions aim to bring the money market interest rate as close to the target level as possible. Still, amid the significant structural liquidity squeeze of 2013-2015, the interest rates usually stayed in the upper part of the corridor. With the structural liquidity surplus increasing in recent months, they usually lie in the lower part of the corridor, i.e., somewhat (but not significantly) below the key rate.

\section{Open questions and inflation targeting implementation in Russia}

In the 1990-2000s, inflation targeting helped many countries slow inflation and keep it low, thereby creating new opportunities for developing their economies and financial markets. However, the 2008 crisis has given rise to new questions. On top of that, the inflation targeting regime itself keeps improving in various countries, allowing better practices to be developed. The book Advancing the Frontiers of Monetary Policy discusses the main controversial issues and provides recommendations for further improvements in inflation targeting practices. Some of these issues, such as policy conduct in a situation of close to zero interest rates, to mention just one, are less relevant to Russia. We will therefore dwell on those which are also relevant to this country.

These are, above all, issues of communications. In particular, the question about whether it is central bank employees or its board of directors members that should come up with a public forecast. Another open question is the one about the publication of interest rate forecasts.

All central banks, which directly or indirectly (as the US Fed), rely on the inflation targeting regime, publish their economic and inflation forecasts, but the forms of these publications vary greatly. In Russia, for example, it is the Governor of the Bank of Russia who makes public the key points of the forecast, while a more detailed analysis and the forecast are published in the evening of the same day as part of the monetary policy report. In some countries, the monetary policy or inflation report is released several days before the board of directors' meeting. In such cases, it is usually emphasized that it is a forecast from the experts of the central bank's relevant units rather than from board members. Alternatively (the US Fed being the most appropriate example), instead of the experts' forecast, an aggregate analysis of forecasts by individual members of the board is published. The book recommends publishing central bank employees' report in advance and describing, as the decision-making process is later disclosed, the difference in the logic of board members and that of employees as set forth in the forecast. In our view, this recommendation is only appropriate for countries where boards of directors include quite a few so-called external members, i.e., experts elected to the board with no governance powers in the central bank itself. This practice is, 
for instance, common to the UK, Mexico, and the above-mentioned USA. These board members usually care very seriously about their reputation and express their own views on monetary policy issues, hence for the market to get an idea of the central bank's policy it is important to know which of the results have been obtained through a model-based analysis by central bank employees and which of them take into account personal views of particular independent board members. No independent board members are appointed in Russia, all of them are central bank employees or executives. They extensively interact with a team of employees engaged in preparing the forecast. That said, the Bank of Russia adheres to a single-voice policy, where no alternative views on policy are supposed to be stated. All the employees engaged in explaining the relevant decision should stick to the same logic. In this framework, the Bank of Russia does not need to make a distinction between its employees' forecast and that by the Bank of Russia. Moreover, the forecast's official status enhances its credibility.

Another of the current hot issues is in what form central banks should provide their forecasts of their future policies. The publication of forecasts has become central banks' common practice, but this practice was somewhat expanded in an environment of close to zero interest rates. The book, however, sets forth a view on normal communications rather than on an unconventional policy under close to zero interest rates. The authors believe that the best practice is the publication of interest rate forecasts together with a general economic forecast in the relevant report prepared by employees. Only a small number of central banks (for instance, those of Norway and the Czech Republic) use this practice, while most of them publish just fairly general comments. Central banks' main concern is that the status of this forecast is unclear and that it can be perceived as a policy commitment. This concern is all the more understandable as in the period of close to zero interest rates unconventional communications regarding future policies were essentially commitments. In the authors' view, this interpretation can be avoided if the forecast is released as part of the employees' report, with this publication describing a relationship between the forecast and other components of economic development scenarios. Moreover, the publication of the forecast helps align central bank and market expectations. In particular, the authors are putting forward a hypothesis that the market response to the US Fed's announcement about its planned departure from quantitative easing in 2013 (the so-called tapering) could have been less volatile, if, instead of generalities, the Fed had published its forecast of possible interest rate changes.

This recommendation by the authors is not, in our view, universally applicable either. The Bank of Russia in most cases relies on a more common practice of general policy comments. This enables our and market expectations to be aligned, while allowing flexible policy adjustment in an environment of multiple structural shocks. The publication of an interest rate path, even subject to reservations, could, in our view, be perceived exactly as a commitment, thus 
not only reducing policy flexibility but also shifting the focus of discussion away from its end goal, inflation, to interim goals. Still, where there is an appreciable divergence between our internal and market interest rate forecasts, we can use clearer communications. In late 2016, the Bank of Russia in effect made a commitment not to revise its interest rate for several months if the situation developed as forecasted. In 2017-2018, the regulator started forecasting the pace of switching to neutral rates as it described the interest rate path.

The last point raising hot debates currently and worth discussing in application to Russia is the use of monetary policy for controlling risks to financial stability. In its current formulation, this issue is not yet quite relevant to Russia. The dilemma which is being widely discussed is whether central banks should maintain low interest rates if inflation remains low but markets see a bubble building up. The Russian experience suggests that bubbles may, especially in some markets, build up even amid fairly high real interest rates. We therefore agree with the authors' conclusions that financial stability is best secured through specially targeted macroprudential instruments. But we also agree that in designing monetary policy, financial conditions and the market situation should be factored in. The financial sector situation is always considered in making an interest rate decision. Also, the Bank of Russia is now designing DSGE models for the financial sector which would allow a more detailed scenario analysis of interdependence between the situation in the financial sector and that in the overall economy.

We note that the book under review extensively discusses the use of the inflation targeting regime in emerging markets and less developed countries. Experiences of India, which has decided to switch to inflation targeting despite massive structural inflation shocks, may be of interest to Russia.

Overall, the analysis of global experience provided by the book shows that structural specifics of an economy and financial markets do not impede the use of the inflation targeting regime. The main problem is a political one, concerned with fiscal domination. This implies that a central bank is directly exposed to political pressure and has to make decisions driven by goals other than inflation control. One version of this problem is an unbalanced fiscal policy placing constraints on monetary policy effectiveness. This is exactly why the budget rule introduced in 2017 enhances the Bank of Russia's effectiveness in achieving inflation targets and helps cut long-term interest rates.

In conclusion, it should be noted that the book is of interest to both central banks themselves and a broader audience of economists and experts. One can draw the details of contemporary central banks' functioning from it and look at discussions on potential improvements in their operations. Some of the book's chapters require specialized knowledge, but a part of the sections can be more readily understood by broader public, people who have basic economic knowledge and are interested in economic policy issues. 